\title{
Forum
}

\section{Will the EC Zoos Directive increase the conservation value of zoo research?}

\author{
Paul A. Rees
}

\begin{abstract}
Article 9 of the Convention on Biological Diversity 1992 requires parties to adopt measures for the ex situ conservation of biodiversity. Within the European Union this has been implemented by the Zoos Directive. The Directive requires zoos and aquariums to adopt a conservation role. Zoos may comply with the Directive by undertaking research from which conservation benefits accrue. However, most current zoo research is concerned with behaviour, environmental enrichment, nutrition and reproduction, and is therefore largely irrelevant to ex situ conservation. It is unlikely that zoos
\end{abstract}

will increase their output of conservation relevant research because most do not have appropriate resources. Furthermore, as an alternative to undertaking research, a zoo may comply with the Directive by engaging in training, information exchange or captive breeding. Most, if not all, zoos already engage in at least one of these activities and therefore may comply with the Directive by doing nothing.

Keywords EC law, research, zoo, Zoos Directive.
Parties to the Convention on Biological Diversity 1992 are required, under Article 9, to adopt measures for the ex situ conservation of biodiversity. This may be defined as 'keeping components of biodiversity alive away from their original habitat or natural environment' (Heywood, 1995). However, these measures are not to be taken as an end in themselves but predominately for the purpose of complementing in situ measures.

Part of the European Union's response to Article 9 was to produce the EC Zoos Directive, with which member states were required to comply by 9 April 2002. The Directive demands high standards of husbandry in zoos and aquariums and also obliges them to adopt a conservation role (Art. 3.). These requirements are to be imposed by the use of a zoo licensing system that gives powers to the national licensing authority of each member state to close any zoo that does not comply. The Directive applies to 'all permanent establishments where animals of wild species are kept for exhibition to the public for 7 or more days a year' (Art. 2). One means of complying with the requirement to adopt a conservation role is to participate in 'research from which conservation benefits accrue to the species.' For the purpose of the current discussion, research is taken to mean

Paul A. Rees School of Environment \& Life Sciences and Research Institute for the Built and Human Environment, Peel Building, University of Salford, Salford, Greater Manchester, M5 4WT, UK. E-mail p.a.rees@salford.ac.uk

Received 14 January 2004. Revision requested 3 June 2004 Accepted 2 July 2004. the systematic collection and analysis of biological data by scientists, or the development of new scientific techniques, as opposed to the day-to-day record keeping performed by keepers.

To date, relatively little zoo research can claim to have conferred a clear conservation benefit on threatened species, although this may be equally true of mainstream academic research on conservation. An analysis of 904 research projects conducted in British and Irish zoos found a highly skewed distribution across 15 subject categories (Semple, 2002). Behavioural studies represented the largest category $(40 \%)$, followed by studies of environmental enrichment (18\%) and reproduction (8\%). Fewer than $5 \%$ of projects studied the genetics, ecology or conservation of a species.

Some behavioural work may be of relevance to conservation, for example where it concerns the study of reproductive behaviour (Laurenson, 1993; Lindburg \& Fitch-Snyder, 1994). However, many feeding behaviour studies are concerned with the beneficial effects of enriching the zoo environment with some kind of feeding device (e.g. Jenny \& Schmid, 2002). The zoo community is currently preoccupied with environmental enrichment that, while often conferring some welfare benefit on zoo animals, has little to do with conservation.

Unless zoos can demonstrate a clear and substantial role in reintroduction programmes much zoo research on reproductive biology is only likely to be of importance in helping zoos to maintain their supply of replacement animals. The recent successes in producing elephants by 
Table 1 The subjects of papers published in Zoo Biology, 1996-2004, and publications of the member institutions of the American Zoo and Aquarium Association (AZA), 1999-2000 (the latter from Lankard, 2001).

\begin{tabular}{llc}
\hline & $\%$ of total & \\
\cline { 2 - 3 } Category & Zoo Biology (n = 349) & AZA (n = 957) \\
\hline Reproductive physiology/technology & 34 & 7 \\
Nutrition/growth/development & 19 & 3 \\
Behaviour/enrichment/ethology & 17 & 9 \\
Medicine/welfare/husbandry & 12 & 7 \\
Taxonomy/genetics/population biology & 10 & 8 \\
Physiology (except reproduction) & 3 & - \\
Ecology/field biology/conservation/reintroduction & 2 & 27 \\
Enclosure design/exhibits & 1 & - \\
Research methods & 1 & - \\
Anatomy & 1 & - \\
Veterinary medicine/physiology & - & 15 \\
Social science/education & - & 7 \\
Unspecified & - & 6 \\
Records/data management & - & 5 \\
Wildlife disease & - & 3 \\
Zoo community policy/philosophy/history & - & 3 \\
\hline
\end{tabular}

artificial insemination (Schwammer et al., 2001) is beneficial to elephant breeding programmes in zoos, but elephants breed perfectly well in the wild, and the threats to wild populations are not the result of low fecundity. Unless and until zoo animals become an important source for reintroduction projects, developments in reproductive technology are irrelevant to conservation efforts, although clearly they may be of great importance for some highly threatened species, for example giant pandas Ailuropoda melanoleuca (Pérez-Garnelo et al., 2004). Zoo bred animals are rarely used in reintroduction projects, although notable exceptions include the European bison Bison bonasus, golden lion tamarin Leontopithecus rosalia, Hawaiian goose Branta sandvicensis, Père David's deer Elaphurus davidianus and Mauritius kestrel Falco punctatus (Anon., 1993; Frankham et al., 2002). For many species little more than a protective zoo environment was required in order to encourage reproduction, but in others (e.g. the Californian condor Gymnogyps californianus) novel rearing techniques have been developed and there can be no doubt that a conservation benefit accrued as a result.

A good deal of zoo research is unsuitable for publication in academic journals. By its very nature, such research is conducted in unnatural conditions and often with small samples of animals. Jenny \& Schmid (2002), for example, studied the effect of feeding boxes on the behaviour of just two tigers. Much of what is published appears in a small number of very specialized journals such as Zoo Biology, the Journal of Zoo and Wildlife Medicine and the International Zoo Yearbook. An analysis of 353 papers published in Zoo Biology between 1982 and 1992 found that $81.3 \%$ concerned mammals (Hardy, 1996).
Of the 287 papers on mammals, $29.6 \%$ were studies of behaviour or behavioural ecology, a further $5.9 \%$ involved behavioural/environmental enrichment and $20.2 \%$ were studies of reproductive biology. Only $3.8 \%$ of papers were concerned with genetics or population biology, and just $2.3 \%$ involved wildlife management. The remainder were concerned with nutrition and diet $(3.5 \%)$, exhibit design and evaluation $(1.2 \%)$, veterinary medicine $(5.6 \%)$, captive management $(24 \%)$ and morphology and development (5.6\%). This analysis was undertaken before the Zoos Directive came into force and covers research from a wide geographical area, not just the EU. However, it gives an indication of the historical focus of zoo research.

An examination of 349 papers published in Zoo Biology between 1996 and mid 2004 (Table 1) suggests a significant change in emphasis in the research carried out by zoos. Reproductive studies now replaced behaviour as the largest category (34\%), followed by studies of nutrition, growth and development (19\%) and behaviour and enrichment (17\%). Studies concerned with ecology, field biology, conservation and reintroduction only accounted for $2 \%$ of the total, but there was an increase in papers on taxonomy, genetics and population biology (10\%).

Hardy (1996) has demonstrated that the popularity of particular research areas is not necessarily reflected in the number of published studies. In an analysis of 302 research projects carried out on mammals by zoo staff in 40 American zoos (Wiese et al., 1992), behavioural and behavioural ecology studies made up $22.8 \%$ of studies undertaken but only $5.3 \%$ of studies published in the same period. Studies of reproductive physiology accounted for only $19.5 \%$ of studies undertaken but 
almost $31 \%$ of all published studies, whereas studies of natural history or fieldwork represented $23.1 \%$ of all published studies but only $16.6 \%$ of studies conducted. Field based studies are likely to be more relevant to conservation than zoo studies. However, while they had a relatively good publication record, field studies represented a small proportion of the total research conducted by zoo staff in this study.

Some taxa are poorly represented in research programmes. Card et al. (1998) conducted a survey of the research activity and conservation programmes of 52 North American zoo reptile and amphibian departments. Of 164 technical papers produced between 1987 and 1997 by the 22 respondent institutions, $79 \%$ were conducted by just three institutions and only 16 field studies were reported. Only one institution received funding specifically for research. Card et al. concluded that zoo herpetology departments were not realizing their potential for formalized research and conservation projects.

Examination of more recent data from North America shows a more encouraging picture. Lankard (2001) lists and categorizes 957 publications produced in 1999-2000 by the member institutions of the American Zoo and Aquarium Association (AZA). The largest research category by far was ecology/field conservation/reintroduction (27\%). However, this encompassed a wide range of publications from status reports on individual taxa and recovery plans to papers on how to record the weather. The next largest category was veterinary medicine/physiology (15\%), followed by behaviour/ethology $(9 \%)$. Studies of reproductive physiology/technology amounted to just $7 \%$ of the total (compared with $34 \%$ of papers in Zoo Biology between 1996 and 2004) and nutrition accounted for only $3 \%$ (Table 1 ).

Some of the discrepancy between the data from the AZA and from the analysis of papers in Zoo Biology for 1996-2004 is because work that can be classified as field biology or conservation, although undertaken by zoo staff, is more likely to be published in a journal focusing on ecology or conservation than one concerned with the work of zoos. The conservation research work of zoos will inevitably be greatly underrepresented in Zoo Biology. In addition, the AZA publications list included a wide range of materials ranging from papers in peer reviewed journals to technical handbooks, studbooks and items in newsletters. A great deal of zoo research is not published in peer reviewed scientific journals and is therefore largely lost to the wider scientific community. One weakness of the Zoos Directive is that it does not require research to be published at all.

The public expects high welfare standards in zoos but does not necessarily expect an obvious conservation role. It is, therefore, perhaps inevitable that zoos will expend a great deal of effort on enrichment projects, thereby creating many opportunities for collecting research data. Much of this behavioural research is of little conservation interest, and is not published. This may be because the data were collected in order to inform management practices within a specific institution. Hardy (1996) has discussed the possible reasons for the poor publication record of zoos, including the possibility that many zoo studies may not produce adequate empirical data for publication.

It is unrealistic to expect the quantity of conservation relevant research from zoos to substantially increase as a result of the Zoos Directive, for a number of reasons. Firstly, few zoos can afford to build research facilities or employ full time researchers, and this will continue to limit the quantity and quality of zoo research. There is evidence of an increased emphasis on research in American zoos. A survey of 173 North American zoos and aquariums (Stoinski et al., 1998) showed an increase in the role of research in AZA institutions in the previous decade, and a doubling of the number of researchers per institution since 1986. However, Stoinski et al. (1998) found that the most common reasons for American zoos not conducting research were lack of funds, time and qualified personnel. This is likely to be true for most European zoos, and so much of the research work is, therefore, likely to continue to be undertaken by keepers and students. Secondly, university researchers who work in zoos are only likely to conduct work that can be published. Finding conservation relevant subjects is more difficult than finding behavioural or physiological subjects, and test and control situations are difficult to set up in a zoo environment. Thirdly, some types of research would raise welfare concerns, for example invasive physiological studies, and would require a government license. Fourthly, and most importantly, there is no incentive for zoos to comply with Article 3 by undertaking appropriate, conservation relevant research because they can legitimately ignore this requirement, provided that they take at least one alternative conservation measure. This may be training in conservation skills, or exchanging information relating to species conservation, or engaging in captive breeding (Art. 3). Most, if not all, zoos already engage in at least one of these activities and therefore may comply with the Directive by doing nothing.

The systematic scholarly use of European menageries began some 350 years ago and expanded during the Enlightenment (Baratay \& Hardouin-Fugier, 2002). Early zoo research was focused on anatomy, physiology and systematics. However, more recently a significant amount of basic research on the biology of zoo animals, which may be of considerable conservation relevance, has been performed by zoological research institutions allied to zoos, for example, the Institute of Zoology in 
London and the Institute for Zoo and Wildlife Research in Berlin. Veterinary studies on zoo animals have led to some developments that have had considerable conservation benefits, for example in the areas of identification and marking (Rice \& Kalk, 1996) and capture, handling and anaesthesia (Bush, 1996). However, they represent a small proportion of all zoo research and much zoo veterinary research is concerned with solving problems associated with captivity. There is some evidence of a recent shift away from behavioural studies and towards work on nutrition, reproduction and genetics (within work published by Zoo Biology). However, the relevance of this type of work to in situ conservation measures has still to be demonstrated.

European Union zoos and their staff should be a significant conservation resource, located, as they are, within some of the richest and most scientifically advanced states in the world. The Zoos Directive was an opportunity to engage the EU zoo community in conservation research. However, it seems unlikely that the Directive will have any significant effect on the relevance of most zoo research to wildlife conservation unless zoos decide for themselves that it should.

\section{References}

Anon. (1993) The World Zoo Conservation Strategy. The Role of the Zoos and Aquaria of the World in Global Conservation. IUDZC-The World Zoo Organization and the Captive Breeding Specialist Group of IUCN/SSC

[http:/ / www.waza.org/conservation/wczs.php, accessed 21 October 2003].

Baratay, E. \& Hardouin-Fugier, E. (2002) Zoo. A History of Zoological Gardens in the West. Reaktion Books Ltd, London, UK.

Bush, M. (1996) Methods of capture, handling and anesthesia. In Wild Mammals in Captivity. Principles and Techniques (eds D.G. Kleiman, M.E. Allen, K.V. Thompson \& S. Lumpkins), pp. 25-40. The University of Chicago Press, Chicago, USA.

Card, W.C., Roberts, D.T. \& Odum, R.A. (1998) Does zoo herpetology have a future? Zoo Biology, 17, 453-462.

Frankham, R., Ballou, J.D. \& Brisoe, D.A. (2002) Introduction to Conservation Genetics. Cambridge University Press, Cambridge, UK.

Hardy, D.F. (1996) Current research activities in zoos. In Wild Mammals in Captivity. Principles and Techniques (eds D.G. Kleiman, M.E Allen, K.V. Thompson \& S. Lumpkins), pp. 531-536. The University of Chicago Press, Chicago, USA.

Heywood, V.H. (ed.) (1995) Global Biodiversity Assessment. United Nations Environment Programme. Cambridge University Press, Cambridge, UK.

Jenny, S. \& Schmid, H. (2002) Effect of feeding boxes on the behaviour of stereotyping Amur tigers (Panthera tigris altaica) in the Zurich Zoo, Zurich, Switzerland. Zoo Biology, 21, 573-584.

Lankard, J.R. (ed.) (2001) AZA Annual Report on Conservation and Science 1999-2000. Volume III: Member Institution Publications. American Zoo and Aquarium Association, Silver Spring, USA.

Laurenson, M.K. (1993) Early maternal behaviour of wild cheetahs: implications for captive husbandry. Zoo Biology, 12, 31-43.

Lindburg, D.G. \& Fitch-Snyder, H. (1994) Use of behaviour to evaluate reproductive problems in captive mammals. Zoo Biology, 13, 433-445.

Pérez-Garnelo, S.S., Garde, J., Pintado, B., Borque, C., Talavera, C., Delclaux, M., López, M. \& Martinez, J. (2004)

Characteristics and in vitro fertilizing ability of giant panda (Ailuropoda melanoleuca) frozen-thawed epididymal spermatozoa obtained 4 hours post-mortem: a case report. Zoo Biology, 23, 279-285.

Rice, C.G. \& Kalk, P. (1996) Identification and marking techniques. In Wild Mammals in Captivity. Principles and Techniques (eds D.G. Kleiman, M.E. Allen, K.V. Thompson \& S. Lumpkins), pp. 56-66. The University of Chicago Press, Chicago, USA.

Schwammer, H.M., Hildebrandt, T. \& Göritz, F. (2001) First successful artificial insemination in an African elephant in Europe. International Zoo News, 48, 424-429.

Semple, S. (2002) Analysis of research projects conducted in Federation collections to 2000. Federation Research Newsletter, 3, 3. Federation of Zoological Gardens of Great Britain and Ireland.

Stoinski, T.S., Lukas, K.E. \& Maple, T.L. (1998) A survey of research in North American zoos and aquariums. Zoo Biology, 17, 167-180.

Wiese, R.J., Hutchins, M., Willis, K. \& Becker, S. (eds) (1992) AAZPA Annual Report on Conservation and Science. American Association of Zoological Parks and Aquariums, Bethesda, USA.

\section{Legislation cited}

Convention on Biological Diversity 1992 United Nations. International Environmental Law-Multilateral Treaties. p.992:42 01/043. 1992.

Council Directive 1992/22/EC of 29 March 1999 relating to the keeping of wild animals in zoos. O.J. No. L 094, 9.4.1999, 24-26.

\section{Biographical sketch}

Paul A. Rees lectures in wildlife ecology and wildlife law at the University of Salford, UK. He has a particular interest in the ecology, behaviour and conservation of elephants, the conservation role of zoos, and the use of legislative tools to protect wildlife. 